\title{
The Role of Autophagy, Mitophagy and Lysosomal Functions in Modulating Bioenergetics and Survival in the Context of Redox and Proteotoxic Damage: Implications for Neurodegenerative Diseases
}

\author{
Matthew Redmann",2, Victor Darley-Usmar',2, Jianhua Zhang1,2,3,* \\ ${ }^{1}$ Center for Free Radical Biology, ${ }^{2}$ Department of Pathology, University of Alabama at Birmingham, \\ ${ }^{3}$ Department of Veterans Affairs, Birmingham VA Medical Center, Birmingham, Alabama 35294, USA
}

[Received June 10, 2015; Revised August 19, 2015; Accepted August 20, 2015]

\begin{abstract}
Redox and proteotoxic stress contributes to age-dependent accumulation of dysfunctional mitochondria and protein aggregates, and is associated with neurodegeneration. The free radical theory of aging inspired many studies using reactive species scavengers such as alpha-tocopherol, ascorbate and coenzyme $Q$ to suppress the initiation of oxidative stress. However, clinical trials have had limited success in the treatment of neurodegenerative diseases. We ascribe this to the emerging literature which suggests that the oxidative stress hypothesis does not encompass the role of reactive species in cell signaling and therefore the interception with reactive species with antioxidant supplementation may result in disruption of redox signaling. In addition, the accumulation of redox modified proteins or organelles cannot be reversed by oxidant intercepting antioxidants and must then be removed by alternative mechanisms. We have proposed that autophagy serves this essential function in removing damaged or dysfunctional proteins and organelles thus preserving neuronal function and survival. In this review, we will highlight observations regarding the impact of autophagy regulation on cellular bioenergetics and survival in response to reactive species or reactive species generating compounds, and in response to proteotoxic stress.
\end{abstract}

Key words: oxidative stress, reductive stress, mitochondrial dysfunction, prions, $\alpha$-synuclein, neurodegenerative diseases

As the population ages, the prevalence of debilitating agerelated diseases increases leading to both significant decreases in the quality of life for the individual and an ever increasing economic burden on society as a whole. Redox and proteotoxic stress, metabolic imbalance, and mitochondrial dysfunction, have all been proposed to be associated with aging [1-6]. A common theme of these processes is that they all regulate autophagy, the process that degrades old, excessive or damaged macromolecules and organelles. Therefore, in response to stress, cell survival is dependent on optimal activation of autophagy. This is particularly important for terminally differentiated cells like neurons. Here we highlight some of the supporting evidence in the role of autophagy, mitophagy and lysosomal functions in modulating bioenergetics and survival in the context of redox and proteotoxic damage: implications for neurodegenerative diseases.

Redox and proteotoxic stress in neuronal aging

Neurons are highly dependent on mitochondrial respiration for their function, including depolarization and homeostasis, and because of their non-dividing nature may have a higher propensity to accumulate oxidative damage, and thus the quality control of their organelles is important [7]. Mitochondrial dysfunction, oxidative and 
nitrative stress are pronounced in neurodegenerative diseases, and contribute to the initiation and progression of neurodegeneration [8-16]. Mitochondria can also both generate and be modified by reactive species. ROS and oxidative stress have also been implicated in the recruitment of specific mitochondrial autophagy proteins [17]. Furthermore, accumulation of oxidatively-modified and aggregated proteins, mitochondrial damage and loss of energy-generating capacity are prominent features in age-dependent neurodegenerative diseases [8]. For instance, the lipid peroxidation product 4-hydroxynonenal (HNE) accumulates as protein adducts in both Parkinson's and Alzheimer's disease brains [18-22].

Mitochondrial DNA mutations and electron transport chain deficits have been detected in Alzheimer's and Parkinson's diseases, with these deficits undoubtedly contributing to disease progression [8-16]. Experimental therapeutic approaches to reduce mitochondrial dysfunction by using a toxin-resistant complex I subunit, enhancing complex II activities, or stabilizing mitochondrial membrane potential [23-25] have been explored. Complex IV is important for mitochondrial respiration, and is sensitive to oxidative and nitrosative stress. Whether its expression serves to stimulate or inhibit signals for mitophagy and changes cellular resistance to oxidative stress are unknown. Translating these studies to successful clinical trials though, is a challenge [26]. Determining what controls mitochondrial fitness is important for a better understanding of neurodegeneration and arming us with the knowledge that may help design better therapeutic strategies. How cellular bioenergetics, oxidative stress and autophagiclysosomal activities are cross regulated is also important. It is clear that mitochondrial activity and oxidative stress are intertwined as mitochondria are sensitive to ROS damage while simultaneously generating ROS for cell signaling. Indeed, inhibiting the mitochondria's antioxidant defense mechanisms is deleterious to not only the mitochondria, but the cell as a whole, as best evidenced by SOD2 deletions or mutations [27]. Furthermore, inhibition of the mitochondrial glutathione transporter increases neuron sensitivity to oxidative and nitrosative stress [28]. The same degree of oxidative stress may then induce variable effects on bioenergetic programs depending on the maintenance of mitochondrial quality and coordination between biogenesis and mitophagy [29].

While uncontrolled levels of ROS are thought to be detrimental, and the accumulation of protein and DNA oxidation products and damaged mitochondria in aging animals has been taken as support for the free radical theory of aging [30,31,31,31], there has also been evidence that challenge this theory, with mild to moderate ROS elevation playing important roles in cell signaling, adaptation and lifespan extension. Manipulation of the enzymes responsible for generation and elimination of ROS does not directly support the idea that high ROS shortens and low ROS extends lifespan [6,32]. Programmed knockdown of mitochondrial complex I, III, IV and V activities may be associated with decreased metabolic rate and thereby contribute to longevity. For example, in worms, knockdown of cytochrome c oxidase1 subunit $\mathrm{Vb}$ (COX4), by transgenic expression of an inverted repeat hairpin directed to COX4 gene in the intestine or neurons enhanced lifespan. COX4 knockdown did not confer resistance to paraquat-induced oxidative stress, UV damage, or heat stress, while inducing the mitochondria-specific unfolded protein response (UPR ${ }^{\text {mito }}$ ) [33]. Mutation of the Rieske iron sulfur protein or a subunit of complex $\mathrm{I}$ of the mitochondrial electron transport chain led to increased lifespan with an associated elevated mitochondrial ROS [34], and an Apaf1 and caspase-9 dependent alteration of transcriptomes in the cell is responsible for the enhanced longevity [35]. Similarly, mutation of a mitochondrial hydroxylase required for ubiquinone production also led to enhanced lifespan and with associated increase of ROS and HIF-1-dependent gene expression [36]. Although in C.elegansdaf- 2 mutation led to decreased mitochondrial activity and decreased ROS levels and increased lifespan, acute impairment of $d a f-2$ in adult worms led to transient increase of ROS, which induced adaptive response and is required for enhanced life span by daf-2 impairment[37]. Further supporting a lack of direct relationship between ROS levels and aging, knockdown of the mitochondrial SOD extended lifespan in worms [38], and the extension of lifespan by overexpression of SOD-1 is not associated with decreased lipid oxidation or glycation, but associated with increased protein oxidation and ER stress and is dependent on the transcription factor FoxO, IRE-1 and XBP-1 [39]. Knockout of all 5 superoxide dismutases (SODs) are not essential for normal lifespan despite markedly increased sensitivity to multiple stresses in worms[40].However, in marked contrast to worms, SOD2 or SOD1 knockout in mice develop cardiomyopathy, neurodegeneration, or neuromuscular junction degeneration, respectively, and decreased lifespan [41-46], while neither SOD1 nor SOD2 overexpression in mice extends lifespan [47]. Although deficiency in proofreading activities of PolG of mitochondrial DNA led to increased somatic mtDNA mutations and decreased lifespan [48], studies in the flies indicated that oxidative stress is not a major contributor to somatic mitochondrial DNA mutations [49].

Taken together, these data cannot be easily reconciled with either the oxidative stress hypothesis or the free radical theory of aging in their simplest manifestations. However, emerging evidence in the redox biology field 
places these findings in a different context. It is now clear that a critical role of intracellular antioxidants, such as glutathione or superoxide dismutase, is to maintain the integrity of redox signaling domains and that reductive stress can be as detrimental as oxidative stress. It has also been shown that mitochondrial ROS (superoxide or hydrogen peroxide) can be generated at multiple sites within the organelle and these are regulated by substrate supply and are not necessarily equivalent with respect to their downstream signaling effects [50-52]. The impact of manipulating these pathways can then only be interpreted in the context of their interaction with metabolism and cell signaling. In this regard, enhanced autophagic activity may provide additional survival signals or mechanisms for the cell to manage either transient or prolonged increases in oxidative damage to proteins as well as damage that occurs independently of ROS in the context of aging and longevity (Figure 1).

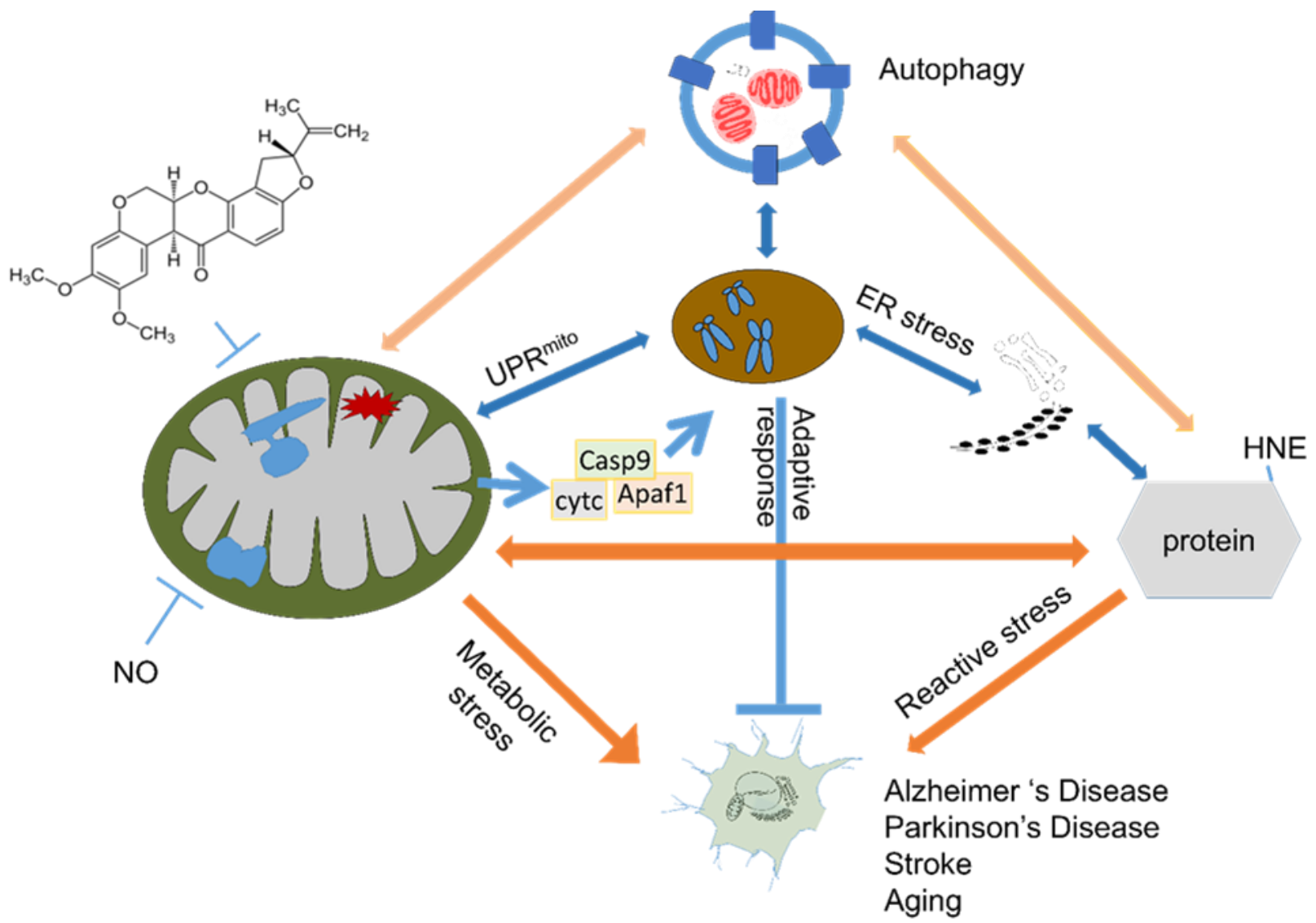

Figure 1. Autophagy serves as an essential neuroprotective pathway in response to mitochondrial dysfunction and oxidative stress. In neurodegenerative diseases, AD, PD, and stroke, mitochondrial dysfunction accumulates due to aging, genetic abnormalities, environmental damage (such as pesticides), or neuroinflammation (which induces excessive production of nitric oxide, among others), resulting in decreased oxidative phosphorylation, and accumulation of mtDNA damage. There are also increases in protein damage, including protein oxidation and formation of HNE-protein adducts. Whether absolute levels of ROS are directly correlated with aging process is debatable. Emerging evidence indicated that transient or moderate ROS elevation may trigger response in ER stress and mitochondrial unfolded protein response pathways, as well as adaptations mediated by HIF, NRF2 and other transcription factorregulated mechanisms (such as Apaf1 and Caspase-9 dependent mitochondria to nuclear signaling). Therefore, a systemic decrease of ROS is unlikely to be the best approach to delay aging and age related neurodegeneration. Clearance of damaged proteins and organelles are dependent on the autophagy process, which involve double membrane vesicles encircling these damaged intracellular materials and sending them to be degraded. It has been hypothesized that dysfunction of autophagy promotes neurodegeneration and enhancement of autophagy may be neuroprotective. 


\section{The role of autophagy and mitophagy in lifespan and neuronal aging}

The importance of autophagy in aging is supported by observations that yeast, C.elegans and flies with impaired autophagy have decreased lifespan. This contributes to the notion that that autophagy plays an important role in the aging [53-55]. Physiologically, autophagy deficient skeletal muscles and pancreatic $\beta$ cells have dysmorphic mitochondria and defective oxidative phosphorylation [56]. PINK1 knockout mice exhibit mitochondrial dysfunction in cultured primary cortical neurons as well as the striatum, liver, and brain[57,58]. Furthermore, pharmacologic or genetic manipulations that increase life span in model organisms often stimulate autophagy [5966]. For example, inhibition of mTOR by rapamycin, which enhances autophagy, extends health span and lifespan in model organisms [67]. The mechanisms of the effect of rapamycin are pleiotropic, including inhibition of protein synthesis, alteration of transcriptomes, modulation of inflammation, and improvement of cerebral blood flow, in addition to regulation of autophagy, mitophagy and thereby mitochondrial function $[59,64,68-80]$.Taken together, these examples provide strong support for the concept that autophagy plays a critical role in maintaining a normal lifespan and healthy neuronal aging, and that its decline is inexorably tied to age related pathologies.

Degradation of dysfunctional mitochondria is carried out by the autophagy-lysosomal pathway. A deficiency in the autophagy protein Atg7 has been shown to cause mitochondrial dysfunction, both in isolated mitochondria from skeletal muscle and in cultured embryonic fibroblasts [56]. Furthermore, intracellular ROS levels were increased in autophagy gene Atg7 knockout cells [56]. Parkin knockout results in aberrant mitochondrial morphology and activities [81]. Many lysosomal diseases result in deficient autophagic degradation of cellular materials. The alteration of mitochondrial morphology and decreased respiratory chain activity varies in both extent and characteristics in tissues and isolated mitochondria among these diseases [82]. The lysosomotropic agent chloroquine or the lysosomal protease cathepsin D inhibitor pepstatin A have both been shown to increase the formation of reactive species [8387]. How in vivo blockade of autophagy impacts mitochondrial morphology and specific respiratory chain activities is not well understood. Understanding this relationship will be crucial in identifying specific targets for therapeutic modulation that are particularly sensitive to autophagic stress associated with neurodegenerative diseases.

Healthy neurons exhibit a significant basal level of autophagic flux, and such flux can be easily attenuated by perturbations of lysosomal activities seen in various lysosomal storage diseases [88-92], and autophagylysosomal degradation system declines with age [93-95]. Enhancing autophagosomal activity without enhancing lysosomal enzyme activities may not be effective. Further, enhancing overall macroautophagy, as in treatments that stimulate the cell to initiate starvation responses, may be detrimental because of a risk of eliminating normal, but essential proteins. Enhancing lysosomal function may increase the efficiency of flux and degradation of already damaged autophagosome sequestered proteins and organelles, thus preserving selectivity for toxic or dysfunctional material, and contributing to neuroprotection. Improving lysosomal biogenesis, increasing specific hydrolases, or decreasing lysosomal protease inhibitors have all been explored as neuroprotective strategies [96-98]. Here we highlight some of the evidence that autophagy may serve as an antioxidant and anti-proteotoxicity pathway and provide a beneficial impact on neuronal bioenergetic health and survival (Figure 1).

The role of autophagy in response to oxidative and nitrosative stress, as well as mitochondrial inhibition in neuronal cells

Mitochondria are targets and generators of oxidative stress and their dysfunction is prominent in age dependent diseases. Therefore assessing mitochondrial function in response to genetic deficits and/or oxidative stress is important. We and others have optimized the technique of using the Seahorse extracellular flux analyzer to measure basal, complex V-linked ATP generation, as well as uncoupling induced maximal oxygen consumption from the mitochondria [99]. Furthermore, using plasma membrane permeabilization agents and supplementing substrates for different mitochondrial respiratory chain components, complexes I, II, IV and V activities can be individually measured in a high throughput manner[100]. These measurements coupled with mtDNA copy number and a mtDNA damage assay [101-105], mitochondrial reactive oxygen species measurements[106], protein level and post-translational modification analyses [107], have allowed us to demonstrate an important role of autophagy in response to starvation, unfolded protein response, and oxidative stress in diverse cell types, including mouse embryonic fibroblast, endothelial cells, $\beta$ islet cells and breast cancer cells[108-112]. These observations suggest that autophagy is important for redox homeostasis, mitochondrial quality control, cell proliferation and survival $[29,113,114]$. Furthermore, we and others have found that autophagy and lysosomal gene expression may be coordinately regulated at transcriptional and posttranscriptional levels, and that genetic mutations of 
autophagy genes lead to abnormal cell and tissue homeostasis [115,116,116-118]. Future studies regarding how autophagy regulation at both transcriptional and post-translational levels in response to diverse stimuli in a wide range of cellular contexts are urgently needed.

Post-mitotic cells do not have the capacity to divide and dilute toxic cellular constituents, and thus may be more susceptible to accumulation of oxidatively damaged proteins. We have investigated the bioenergetic difference between proliferating neuroblastoma and differentiated neuroblastoma SH-SY5Y cells. We found that differentiated SH-SY5Y cells exhibited increased mitochondrial membrane potential as assessed by JC-1 red/green fluorescence, increased maximal oxygen consumption rate and decreased extracellular acidification rate, while basal oxygen consumption rate, mitochondrial DNA copy number and citrate synthase activities normalized to total protein remain the same[119]. Consistent with a higher reserve bioenergetic capacity, the differentiated cells exhibit higher resistance to mitochondrial inhibition and cell death induced by lipid peroxidation product HNE or intracellular ROS generator, 2,3-dimethoxy-1,4-napthoquinone (DMNQ)[119]. We found that in the differentiated SH-SY5Y cells, different neurotoxins have significantly different impact on cellular bioenergetics at similar toxicity doses, indicating distinct mechanisms of action which cannot be explained by simply inhibiting complex I[99,119,120].Glycolytic activities play an important role in supporting basal and HNE-induced autophagy as well[121].

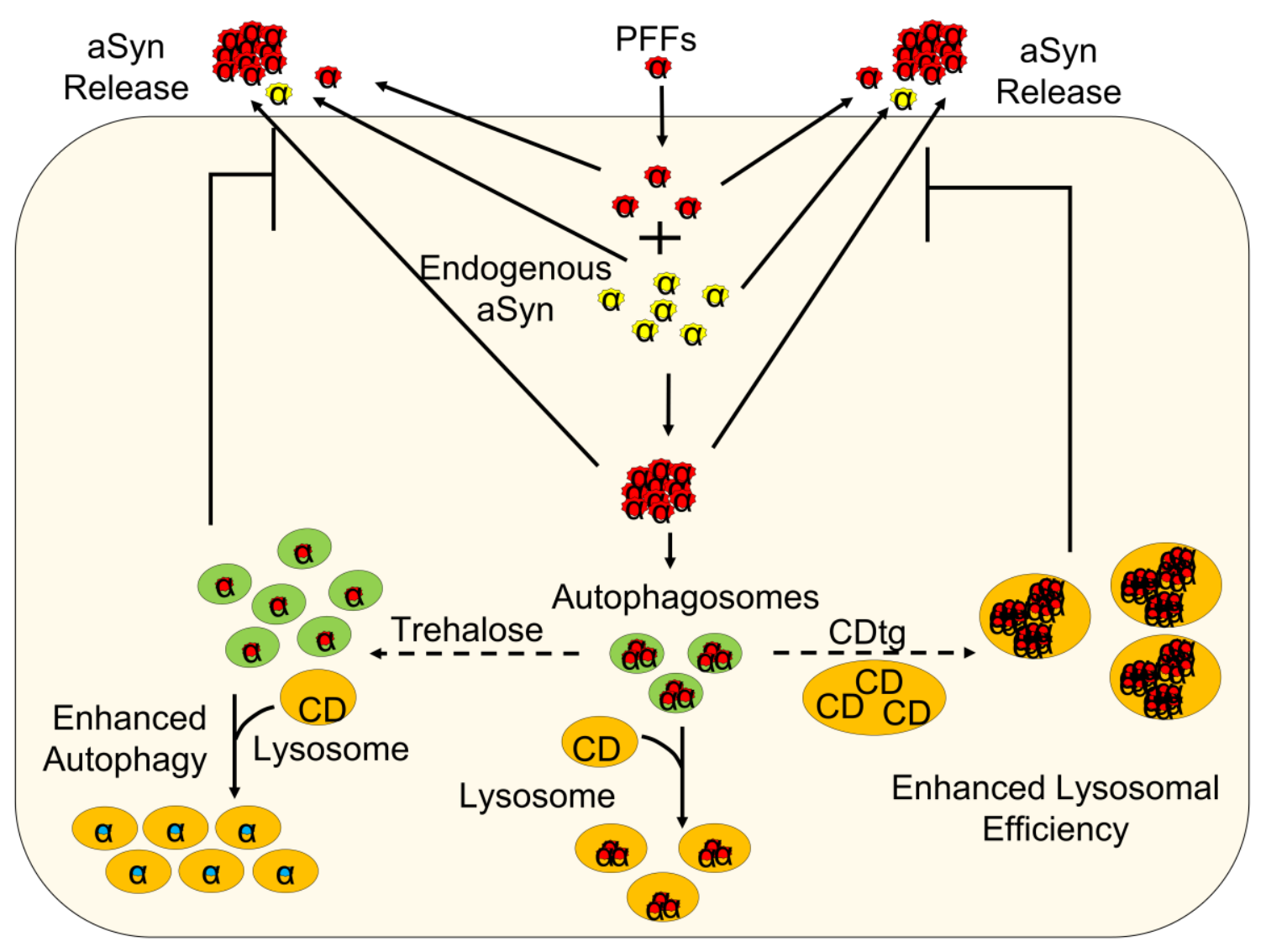

Figure 2. Autophagy may be used to attenuate $\alpha$-synuclein secretion and inter-cellular propagation. $\alpha$-synuclein fibrils (PFF) (red circles) recruit endogenous $\alpha$-synuclein (aSyn) (yellow circles) to form aggregates and induce neuron death. Aggregates can also be released and propagate to neighboring cells and further pathological damage to the brain. Enhanced lysosomal efficiency/hydrolytic capacity through increased Cathepsin D or enhanced autophagosome production through trehalose treatment may promote the sequestering and degradation of toxic $\alpha$-synuclein species. 
Rotenone has been shown to be one of the pesticides linked to increased risk for Parkinson's disease due to its potent inhibitory effects on mitochondrial complex I [122-125]. Furthermore, injection of rotenone into rats and oral administration to mice induced $\alpha$-synuclein accumulation and dopaminergic neurodegeneration $[126,127]$. We found that in live rat primary cortical neurons, rotenone as low as $10 \mathrm{nM}$ induced immediate mitochondrial respiratory inhibition. Although autophagic flux is inhibited by $10 \mathrm{nM}$ rotenone, mitophagy is increased. Cell death is attenuated by the autophagy stimulator rapamycin and exacerbated by the autophagy inhibitor 3-methyladenine (3-MA). With regard to neuronal bioenergetics, reprogramming of mitochondrial substrate usage associated with both complex I and complex II activities occurred in response to rapamycin [128]. In comparison, neuronal response to nitric oxide is highly dependent on oxygen tension, as nitric oxide donors significantly inhibited basal oxygen consumption in hypoxia ( $1 \%$ oxygen) but not in normoxia ( $20 \%$ oxygen). The recovery of mitochondrial respiration in reoxygenation is incomplete, consistent with irreversible damage due to the exposure of neurons to nitric oxide and/or superoxide generated from the mitochondrion. The recovery is further attenuated in the presence of the autophagy inhibitor 3-MA, further demonstrating an essential role of autophagy in preserving neuronal bioenergetics [110]. Taken together, autophagy plays an important role in mitochondrial quality control and neuronal survival (Figure 1).

\section{The role of autophagy in response to proteotoxicity}

One of the prototypical neurodegenerative diseases, Parkinson's disease, is characterized by the progressive and currently unstoppable loss of dopaminergic neurons in the substantia nigra and many other brain regions (18). One dominant defining feature shared among Parkinson's and other neuropathologies, including dementia with Lewy bodies and multiple systems atrophy, is the accumulation of $\alpha$-synuclein(19-21). One critical issue for $\alpha$-synuclein pathology is that it can leave the cell and seed aggregations in neighboring cells, acting in a prionlike fashion (12). The spread of $\alpha$-synuclein is worsened by autophagic decline, a pattern observed in PD models[129]. This presents an important mechanism for disease progression, and warrants serious consideration for therapeutic development. How $\alpha$-synuclein leaves the cell and seeds aggregations elsewhere is still unclear, but exosomal or exocytosis-mediated mechanisms, along with direct diffusion through plasma membranes, have been proposed (22-24). Notably and central to our research focus is the observation that a decrease in lysosomal function promotes the release of $\alpha$-synuclein from the cell, and that $\alpha$-synuclein can seed further aggregation in a new population of cells (24).

Many $\alpha$-synuclein overexpression models have been generated in rodents, each tests a specific aspect of neurodegeneration, although none fully recapitulate human disease pathogenesis (25-29). Recent work demonstrated that preformed $\alpha$-synuclein fibrils can be taken up into neurons and seed the formation of endogenous $\alpha$-synuclein aggregates that resemble many aspects of Lewy body and Lewy neurite pathologies, including forming insoluble, ubiquitinated and phosphorylated high molecular weight species that further amplify disease pathogenesis (Figure 2) $(12,16,17)$. Major protein degradation pathways in neurons include the proteasome, chaperone-mediated autophagy and macroautophagy. For two of these pathways the lysosome is the rate-limiting step in neurons (13). Increasing autophagy initiation without increasing lysosomal mediated degradation may not be effective in degrading $\alpha$-synuclein and attenuating its propagation. Human patients who lack functional Cathepsin D whether by protein truncation, misfolding, or depletion results in congenital neuronal ceroid-lipofuscinosis (NCL), a disease that results in rapid neurodegeneration and death within hours to weeks after birth (46). Cathepsin D knockout mice were found to exhibit a similar phenotype, ultimately leading to death at approximately p25 (47). Chemical inhibition of proteasomal function does not consistently produce $\alpha$-synuclein accumulation in animal models $(30,31)$, whereas we and others have found that autophagy deficiency in cathepsin D mutant humans and animal models resulted in significant aSyn accumulation $(1,14,32,33)$. Furthermore, we have previously shown that overexpression of wildtype Cathepsin $\mathrm{D}$, but not cathepsin B, L, or mutant Cathepsin D, decreased $\alpha$ synuclein toxicity in worms in vivo and mammalian cells in vitro (1). We also found that in addition to Cathepsin $\mathrm{D}$, Cathepsins $\mathrm{B}$ and $\mathrm{L}$ also protects against mutant huntingtin-induced neuron death, while inhibition of autophagy-lysosomal functions by 3-MA, E64d, Pepstatin A exacerbated mutant huntingtin-induced neuron death [130]. These observations indicate that lysosomal function and efficiency are crucial in normal cellular function, and that its enhancement may be beneficial in promoting the removal of toxic long-lived proteins.

One of the major regulators of macroautophagy is the mammalian target of rapamycin (mTOR). Activation of autophagy by rapamycin and its derivatives, via inhibition of mTOR, has shown benefits in cell and animal models as treatments for neurodegenerative diseases (35), however, mTOR inhibition also leads to decreased protein synthesis; furthermore, side effects of rapamycin in humans limit its use, especially over the long term. Furthermore, rapamycin fails to clear intracellular 
aggregates that are resultant from preformed $\alpha$-synuclein fibril exposure and ultimately exacerbating cell death. [131]. mTOR independent autophagy activators have also been found, one of them being trehalose, which is considered safe for human use at doses up to $50 \mathrm{~g}$ in drinking water (36). Although no epidemiology studies have been performed to correlate its consumption with PD incidence, trehalose has been shown to activate autophagy and decrease $\alpha$-synuclein aggregates in PC12 cells (37), decrease Tau accumulation in mice (38), and decrease neurodegeneration in amyotrophic lateral sclerosis (39), Huntington's (40), and Alzheimer's (41) disease models. Trehalose has been shown to be safe with no use limits in Korea and Taiwan, up to 5\% in food in UK, and in 2000 the US FDA gave a letter of no objection to a GRAS Notice for human consumption (42). In drinking water at a concentration of $1-5 \%$, at several age groups from 3 weeks to 4 months, trehalose has been shown to be beneficial in increasing autophagy, while decreasing the accumulation of Tau and dopaminergic neuron death, and improving behavioral performance in Parkin knockout mice overexpressing human mutated Tau protein (38-41). Although the exact mechanism of its action is unclear, one potential mechanism may be activation of the transcription factor TFEB which activates more than 30 autophagy and lysosomal genes; however other mechanisms may also contribute to its action (43-45). Modulation of TFEB alone has also shown promise, where its genetic overexpression of pharmacologic induction has been shown to promote $\alpha$-synuclein degradation [132,133]. Nonetheless, increasing the overall lysosomal numbers may or may not be effective in attenuating $\alpha$-synuclein aggregate formation after neurons are exposed to $\alpha$-synuclein fibrils, since it has been shown that lysosomal cathepsin B may promote aggregate formation [134].

In addition to aberrant accumulation of toxic protein species, mitochondrial dysfunction has also been reported to be in widespread brain areas, including both the substantia nigra and the cortex in Parkinson's disease brains [9,135-137]. How mitochondrial dysfunction is produced is unclear. Environmental toxins such as rotenone and paraquat that damage mitochondria have been shown to induce dopaminergic degeneration in animal models and increase Parkinson's disease risk in humans [122-124]. Importantly, $\alpha$-synuclein can target to mitochondria via an N-terminal cryptic sequence [138], decrease complex I activity and increase the production of reactive oxygen species [138-146]. Prior studies investigated the effects of bypassing complex I blockade via supplying a toxin-resistant subunit, enhancing complex II activities, stabilizing mitochondrial membrane potential [23-25], or enhancing reactive oxygen species clearance [26,147-149] in various animal models.
However, clinical trials based on these direct approaches have had limited success. The limitations include the possibilities of perturbing cellular bioenergetics and redox signaling, and the inability to reverse already propagated damage to proteins and organelles. An alternative approach to improving bioenergetic function in response to $\alpha$-synuclein accumulation may be to enhance autophagy-lysosomal activities [150].

\section{Conclusion}

Reactive damage to proteins and organelles contributes to age-dependent accumulation of dysfunctional mitochondria and protein aggregates and is associated with neurodegeneration. Autophagy has been shown to play a protective role in cellular response to reactive oxygen and nitrogen species as well as toxic proteins. Further investigation of the mechanistic and regulatory elements of autophagy and their respective contributions as a function of time on age related disease pathogenesis will provide important insights into designing therapeutics to stall disease progression.

\section{Acknowledgment}

This work was supported by NIHR01-NS064090 (to JZ).

\section{References}

[1] Finkel T, and Holbrook NJ (2000). Oxidants, oxidative stress and the biology of ageing. Nature, 408:239-247.

[2] Salmon AB, Richardson A, Perez VI (2010). Update on the oxidative stress theory of aging: does oxidative stress play a role in aging or healthy aging? Free Radic Biol Med, 48:642-655.

[3] Houtkooper RH, Williams RW, Auwerx J (2010). Metabolic networks of longevity. Cell, 142:9-14.

[4] Houtkooper RH, Mouchiroud L, Ryu D, Moullan N, Katsyuba E, Knott G et al (2013). Mitonuclear protein imbalance as a conserved longevity mechanism. Nature, 497:451-457.

[5] Solon-Biet SM, McMahon AC, Ballard JW, Ruohonen $\mathrm{K}$, Wu LE, Cogger VC et al (2014). The ratio of macronutrients, not caloric intake, dictates cardiometabolic health, aging, and longevity in ad libitum-fed mice. Cell Metab, 19:418-430.

[6] Yun J, and Finkel T (2014). Mitohormesis. Cell Metab, 19:757-766.

[7] Detmer SA, and Chan DC (2007). Functions and dysfunctions of mitochondrial dynamics. Nat Rev Mol Cell Biol, 8:870-879.

[8] Malkus KA, Tsika E, Ischiropoulos H (2009). Oxidative modifications, mitochondrial dysfunction, and impaired protein degradation in Parkinson's disease: how neurons are lost in the Bermuda triangle. Mol Neurodegener, 4:24. 
[9] Parker WD, Jr., Parks JK, Swerdlow RH (2008). Complex I deficiency in Parkinson's disease frontal cortex. Brain Res, 1189:215-218.

[10] Schapira AH (2008). Mitochondria in the aetiology and pathogenesis of Parkinson's disease. Lancet Neurol, 7:97-109.

[11] Muller WE, Eckert A, Kurz C, Eckert GP, Leuner K (2010). Mitochondrial dysfunction: common final pathway in brain aging and Alzheimer's disease-therapeutic aspects. Mol Neurobiol, 41:159-171.

[12] Querfurth HW, and LaFerla FM (2010). Alzheimer's disease. N Engl J Med, 362:329-344.

[13] Santos RX, Correia SC, Wang X, Perry G, Smith MA, Moreira PI et al (2010). A synergistic dysfunction of mitochondrial fission/fusion dynamics and mitophagy in Alzheimer's disease. J Alzheimers Dis, 20 Suppl 2:S401-S412.

[14] Hauptmann S, Scherping I, Drose S, Brandt U, Schulz KL, Jendrach $M$ et al (2008). Mitochondrial dysfunction: An early event in Alzheimer pathology accumulates with age in AD transgenic mice. Neurobiol Aging.

[15] Crouch PJ, Cimdins K, Duce JA, Bush AI, Trounce IA (2007). Mitochondria in aging and Alzheimer's disease. Rejuvenation Res, 10:349-357.

[16] Moreira PI, Santos MS, Oliveira CR (2007). Alzheimer's disease: a lesson from mitochondrial dysfunction. Antioxid Redox Signal, 9:1621-1630.

[17] Joselin AP, Hewitt SJ, Callaghan SM, Kim RH, Chung YH, Mak TW et al (2012). ROS-dependent regulation of Parkin and DJ-1 localization during oxidative stress in neurons. Hum Mol Genet, 21:4888-4903.

[18] Crifo C, Capuozzo E, Siems W, Salerno C (2005). Inhibition of ion transport ATPases by HNE. Biofactors, 24:137-140.

[19] Crifo C, Siems W, Soro S, Salerno C (2005). Inhibition of defective adenylosuccinate lyase by HNE: a neurological disease that may be affected by oxidative stress. Biofactors, 24:131-136.

[20] Siems W, Grune T, Sommerburg O, Flohe L, Cadenas E (2005). HNE and Further Lipid Peroxidation Products. Biofactors, 24:1-4.

[21] Castellani RJ, Perry G, Siedlak SL, Nunomura A, Shimohama S, Zhang J et al (2002). Hydroxynonenal adducts indicate a role for lipid peroxidation in neocortical and brainstem Lewy bodies in humans. Neurosci Lett, 319:25-28.

[22] Sayre LM, Zelasko DA, Harris PL, Perry G, Salomon RG, Smith MA (1997). 4-Hydroxynonenal-derived advanced lipid peroxidation end products are increased in Alzheimer's disease. J Neurochem, 68:2092-2097.

[23] Marella M, Seo BB, Nakamaru-Ogiso E, Greenamyre JT, Matsuno-Yagi A, Yagi T (2008). Protection by the NDI1 gene against neurodegeneration in a rotenone rat model of Parkinson's disease. PLoS ONE, 3:e1433.

[24] Tieu K, Perier C, Caspersen C, Teismann P, Wu DC, Yan SD et al (2003). D-beta-hydroxybutyrate rescues mitochondrial respiration and mitigates features of Parkinson disease. J Clin Invest, 112:892-901.
[25] Reeves MB, Davies AA, McSharry BP, Wilkinson GW, Sinclair JH (2007). Complex I binding by a virally encoded RNA regulates mitochondria-induced cell death. Science, 316:1345-1348.

[26] Storch A, Jost WH, Vieregge P, Spiegel J, Greulich W, Durner J et al (2007). Randomized, double-blind, placebo-controlled trial on symptomatic effects of coenzyme Q(10) in Parkinson disease. Arch Neurol, 64:938-944.

[27] Li Y, Huang TT, Carlson EJ, Melov S, Ursell PC, Olson JL et al (1995). Dilated cardiomyopathy and neonatal lethality in mutant mice lacking manganese superoxide dismutase. Nat Genet, 11:376-381.

[28] Wilkins HM, Kirchhof D, Manning E, Joseph JW, Linseman DA (2013). Mitochondrial glutathione transport is a key determinant of neuronal susceptibility to oxidative and nitrosative stress. J Biol Chem, 288:5091-5101.

[29] Hill BG, Benavides GA, Lancaster JR, Jr., Ballinger S, Dell'italia L, Zhang J et al (2012). Integration of cellular bioenergetics with mitochondrial quality control and autophagy. Biol Chem, 393:1485-1512.

[30] Harman D (1956). Aging: a theory based on free radical and radiation chemistry. J Gerontol, 11:298-300.

[31] Lopez-Otin C, Blasco MA, Partridge L, Serrano M, Kroemer G (2013). The hallmarks of aging. Cell, 153:1194-1217.

[32] Ristow M, and Schmeisser K (2014). Mitohormesis: Promoting Health and Lifespan by Increased Levels of Reactive Oxygen Species (ROS). Dose Response, 12:288-341.

[33] Durieux J, Wolff S, Dillin A (2011). The cell-nonautonomous nature of electron transport chainmediated longevity. Cell, 144:79-91.

[34] Yang W, and Hekimi S (2010). A mitochondrial superoxide signal triggers increased longevity in Caenorhabditis elegans. PLoS Biol, 8:e1000556.

[35] Yee C, Yang W, Hekimi S (2014). The intrinsic apoptosis pathway mediates the pro-longevity response to mitochondrial ROS in C. elegans. Cell, 157:897-909.

[36] Lee SJ, Hwang AB, Kenyon C (2010). Inhibition of respiration extends $C$. elegans life span via reactive oxygen species that increase HIF-1 activity. Curr Biol, 20:2131-2136.

[37] Zarse K, Schmeisser S, Groth M, Priebe S, Beuster G, Kuhlow D et al (2012). Impaired insulin/IGF1 signaling extends life span by promoting mitochondrial L-proline catabolism to induce a transient ROS signal. Cell Metab, 15:451-465.

[38] Van Raamsdonk JM, and Hekimi S (2009). Deletion of the mitochondrial superoxide dismutase sod-2 extends lifespan in Caenorhabditis elegans. PLoS Genet, 5:e1000361.

[39] Cabreiro F, Ackerman D, Doonan R, Araiz C, Back P, Papp D et al (2011). Increased life span from overexpression of superoxide dismutase in Caenorhabditis elegans is not caused by decreased oxidative damage. Free Radic Biol Med, 51:1575-1582. 
[40] Van Raamsdonk JM, and Hekimi S (2012). Superoxide dismutase is dispensable for normal animal lifespan. Proc Natl Acad Sci U S A, 109:5785-5790.

[41] Lebovitz RM, Zhang H, Vogel H, Cartwright J, Jr., Dionne L, Lu N et al (1996). Neurodegeneration, myocardial injury, and perinatal death in mitochondrial superoxide dismutase-deficient mice. Proc Natl Acad Sci U S A, 93:9782-9787.

[42] Muller FL, Song W, Liu Y, Chaudhuri A, Pieke-Dahl $\mathrm{S}$, Strong R et al (2006). Absence of CuZn superoxide dismutase leads to elevated oxidative stress and acceleration of age-dependent skeletal muscle atrophy. Free Radic Biol Med, 40:1993-2004.

[43] 43. Jang YC, Lustgarten MS, Liu Y, Muller FL, Bhattacharya A, Liang $\mathrm{H}$ et al (2010). Increased superoxide in vivo accelerates age-associated muscle atrophy through mitochondrial dysfunction and neuromuscular junction degeneration. FASEB J, 24:1376-1390.

[44] Flood DG, Reaume AG, Gruner JA, Hoffman EK, Hirsch JD, Lin YG et al (1999). Hindlimb motor neurons require $\mathrm{Cu} / \mathrm{Zn}$ superoxide dismutase for maintenance of neuromuscular junctions. Am J Pathol, 155:663-672.

[45] Larkin LM, Davis CS, Sims-Robinson C, Kostrominova TY, Van RH, Richardson A et al (2011). Skeletal muscle weakness due to deficiency of CuZnsuperoxide dismutase is associated with loss of functional innervation. Am J Physiol Regul Integr Comp Physiol, 301:R1400-R1407.

[46] Sims-Robinson C, Bakeman A, Rosko A, Glasser R, Feldman EL (2015). The Role of Oxidized Cholesterol in Diabetes-Induced Lysosomal Dysfunction in the Brain. Mol Neurobiol. In press.

[47] Perez VI, Van RH, Bokov A, Epstein CJ, Vijg J, Richardson A (2009). The overexpression of major antioxidant enzymes does not extend the lifespan of mice. Aging Cell, 8:73-75.

[48] Trifunovic A, Wredenberg A, Falkenberg M, Spelbrink JN, Rovio AT, Bruder CE et al (2004). Premature ageing in mice expressing defective mitochondrial DNA polymerase. Nature, 429:417-423.

[49] Itsara LS, Kennedy SR, Fox EJ, Yu S, Hewitt JJ, Sanchez-Contreras M et al (2014). Oxidative stress is not a major contributor to somatic mitochondrial DNA mutations. PLoS Genet, 10:e1003974.

[50] Lin TK, Hughes G, Muratovska A, Blaikie FH, Brookes PS, Darley-Usmar V et al (2002). Specific modification of mitochondrial protein thiols in response to oxidative stress: a proteomics approach. J Biol Chem, 277:1704817056.

[51] Higdon A, Diers AR, Oh JY, Landar A, Darley-Usmar VM (2012). Cell signalling by reactive lipid species: new concepts and molecular mechanisms. Biochem J, 442:453-464.

[52] Quinlan CL, Perevoshchikova IV, Hey-Mogensen M, Orr AL, Brand MD (2013). Sites of reactive oxygen species generation by mitochondria oxidizing different substrates. Redox Biol, 1:304-312.
[53] Takacs-Vellai K, Vellai T, Puoti A, Passannante M, Wicky C, Streit A et al (2005). Inactivation of the autophagy gene bec-1 triggers apoptotic cell death in $\mathrm{C}$. elegans. Curr Biol, 15:1513-1517.

[54] Juhasz G, Erdi B, Sass M, Neufeld TP (2007). Atg7dependent autophagy promotes neuronal health, stress tolerance, and longevity but is dispensable for metamorphosis in Drosophila. Genes Dev, 21:30613066.

[55] Toth ML, Sigmond T, Borsos E, Barna J, Erdelyi P, Takacs-Vellai K et al (2008). Longevity pathways converge on autophagy genes to regulate life span in Caenorhabditis elegans. Autophagy, 4:330-338.

[56] Wu JJ, Quijano C, Chen E, Liu H, Cao L, Fergusson MM et al (2009). Mitochondrial dysfunction and oxidative stress mediate the physiological impairment induced by the disruption of autophagy. Aging (Albany NY), 1:425-437.

[57] Gispert S, Ricciardi F, Kurz A, Azizov M, Hoepken $\mathrm{HH}$, Becker D et al (2009). Parkinson phenotype in aged PINK1-deficient mice is accompanied by progressive mitochondrial dysfunction in absence of neurodegeneration. PLoS ONE, 4:e5777.

[58] 58. Gautier CA, Kitada T, Shen J (2008). Loss of PINK1 causes mitochondrial functional defects and increased sensitivity to oxidative stress. Proc Natl Acad Sci U S A, 105:11364-11369.

[59] Harrison DE, Strong R, Sharp ZD, Nelson JF, Astle CM, Flurkey K et al (2009). Rapamycin fed late in life extends lifespan in genetically heterogeneous mice. Nature, 460:392-395.

[60] Vellai T, Takacs-Vellai K, Sass M, Klionsky DJ (2009). The regulation of aging: does autophagy underlie longevity? Trends Cell Biol, 19:487-494.

[61] Vellai T (2009). Autophagy genes and ageing. Cell Death Differ, 16:94-102.

[62] Madeo F, Tavernarakis N, Kroemer G (2010). Can autophagy promote longevity? Nat Cell Biol, 12:842846.

[63] Morselli E, Maiuri MC, Markaki M, Megalou E, Pasparaki A, Palikaras K et al (2010). Caloric restriction and resveratrol promote longevity through the Sirtuin-1-dependent induction of autophagy. Cell Death Dis, 1:e10.

[64] Bjedov I, and Partridge L (2011). A longer and healthier life with TOR down-regulation: genetics and drugs. Biochem Soc Trans, 39:460-465.

[65] Mai S, Muster B, Bereiter-Hahn J, Jendrach M (2012). Autophagy proteins LC3B, ATG5 and ATG12 participate in quality control after mitochondrial damage and influence lifespan. Autophagy, 8:47-62.

[66] Pyo JO, Yoo SM, Ahn HH, Nah J, Hong SH, Kam TI et al (2013). Overexpression of Atg5 in mice activates autophagy and extends lifespan. Nat Commun, 4:2300.

[67] Li J, Kim SG, Blenis J (2014). Rapamycin: one drug, many effects. Cell Metab, 19:373-379.

[68] Lamming DW, Ye L, Katajisto P, Goncalves MD, Saitoh M, Stevens DM et al (2012). Rapamycininduced insulin resistance is mediated by mTORC2 loss 
and uncoupled from longevity. Science, 335:16381643.

[69] Halloran J, Hussong SA, Burbank R, Podlutskaya N, Fischer KE, Sloane LB et al (2012). Chronic inhibition of mammalian target of rapamycin by rapamycin modulates cognitive and non-cognitive components of behavior throughout lifespan in mice. Neuroscience, 223:102-113.

[70] Majumder S, Caccamo A, Medina DX, Benavides AD, Javors MA, Kraig E et al (2012). Lifelong rapamycin administration ameliorates age-dependent cognitive deficits by reducing IL-1beta and enhancing NMDA signaling. Aging Cell, 11:326-335.

[71] Richardson A (2013). Rapamycin, anti-aging, and avoiding the fate of Tithonus. J Clin Invest, 123:32043206.

[72] Lin AL, Zheng W, Halloran JJ, Burbank RR, Hussong SA, Hart MJ et al (2013). Chronic rapamycin restores brain vascular integrity and function through NO synthase activation and improves memory in symptomatic mice modeling Alzheimer's disease. J Cereb Blood Flow Metab, 33:1412-1421.

[73] Richardson A, Galvan V, Lin AL, Oddo S (2014). How longevity research can lead to therapies for Alzheimer's disease: The rapamycin story. Exp Gerontol.

[74] Liu Y, Diaz V, Fernandez E, Strong R, Ye L, Baur JA et al (2014). Rapamycin-induced metabolic defects are reversible in both lean and obese mice. Aging (Albany NY), 6:742-754.

[75] Fok WC, Chen Y, Bokov A, Zhang Y, Salmon AB, Diaz V et al (2014). Mice fed rapamycin have an increase in lifespan associated with major changes in the liver transcriptome. PLoS ONE, 9:e83988.

[76] Zhang Y, Bokov A, Gelfond J, Soto V, Ikeno Y, Hubbard G et al (2014). Rapamycin extends life and health in C57BL/6 mice. J Gerontol A Biol Sci Med Sci, 69:119-130.

[77] Tardif S, Ross C, Bergman P, Fernandez E, Javors M, Salmon A et al (2015). Testing efficacy of administration of the antiaging drug rapamycin in a nonhuman primate, the common marmoset. J Gerontol A Biol Sci Med Sci, 70:577-588.

[78] Miller RA, Harrison DE, Astle CM, Fernandez E, Flurkey K, Han M et al (2014). Rapamycin-mediated lifespan increase in mice is dose and sex dependent and metabolically distinct from dietary restriction. Aging Cell, 13:468-477.

[79] Hansen M, Taubert S, Crawford D, Libina N, Lee SJ, Kenyon C (2007). Lifespan extension by conditions that inhibit translation in Caenorhabditis elegans. Aging Cell, 6:95-110.

[80] Selman C, Tullet JM, Wieser D, Irvine E, Lingard SJ, Choudhury AI et al (2009). Ribosomal protein S6 kinase 1 signaling regulates mammalian life span. Science, 326:140-144.

[81] Mortiboys H, Thomas KJ, Koopman WJ, Klaffke S, bou-Sleiman P, Olpin S et al (2008). Mitochondrial function and morphology are impaired in parkin-mutant fibroblasts. Ann Neurol, 64:555-565.
[82] Jolly RD, Brown S, Das AM, Walkley SU (2002). Mitochondrial dysfunction in the neuronal ceroidlipofuscinoses (Batten disease). Neurochem Int, 40:565-571.

[83] Rouschop KM, Ramaekers CH, Schaaf MB, Keulers TG, Savelkouls KG, Lambin P et al (2009). Autophagy is required during cycling hypoxia to lower production of reactive oxygen species. Radiother Oncol, 92:411416.

[84] Park BC, Park SH, Paek SH, Park SY, Kwak MK, Choi $\mathrm{HG}$ et al (2008). Chloroquine-induced nitric oxide increase and cell death is dependent on cellular GSH depletion in A172 human glioblastoma cells. Toxicol Lett, 178:52-60.

[85] Farombi EO (2006). Genotoxicity of chloroquine in rat liver cells: protective role of free radical scavengers. Cell Biol Toxicol, 22:159-167.

[86] Park J, Choi K, Jeong E, Kwon D, Benveniste EN, Choi $C$ (2004). Reactive oxygen species mediate chloroquine-induced expression of chemokines by human astroglial cells. Glia, 47:9-20.

[87] Yamasaki R, Zhang J, Koshiishi I, Sastradipura Suniarti DF, Wu Z, Peters C et al (2007). Involvement of lysosomal storage-induced p38 MAP kinase activation in the overproduction of nitric oxide by microglia in cathepsin D-deficient mice. Mol Cell Neurosci, 35:573584.

[88] Boland B, Kumar A, Lee S, Platt FM, Wegiel J, Yu WH et al (2008). Autophagy induction and autophagosome clearance in neurons: relationship to autophagic pathology in Alzheimer's disease. J Neurosci, 28:69266937.

[89] Koike M, Shibata M, Waguri S, Yoshimura K, Tanida I, Kominami E et al (2005). Participation of autophagy in storage of lysosomes in neurons from mouse models of neuronal ceroid-lipofuscinoses (Batten disease). Am J Pathol, 167:1713-1728.

[90] Nakanishi H, Zhang J, Koike M, Nishioku T, Okamoto Y, Kominami E et al (2001). Involvement of nitric oxide released from microglia-macrophages in pathological changes of cathepsin D-deficient mice. J Neurosci, 21:7526-7533.

[91] Saftig P, Hetman M, Schmahl W, Weber K, Heine L, Mossmann $\mathrm{H}$ et al (1995). Mice deficient for the lysosomal proteinase cathepsin D exhibit progressive atrophy of the intestinal mucosa and profound destruction of lymphoid cells. EMBO J, 14:3599-3608. Koike M, Nakanishi H, Saftig P, Ezaki J, Isahara K, Ohsawa Y et al (2000). Cathepsin D deficiency induces lysosomal storage with ceroid lipofuscin in mouse CNS neurons. J Neurosci, 20:6898-6906.

[93] Cuervo AM, and Dice JF (2000). When lysosomes get old. Exp Gerontol, 35:119-131.

[94] Chu Y, Dodiya H, Aebischer P, Olanow CW, Kordower $\mathrm{JH}$ (2009). Alterations in lysosomal and proteasomal markers in Parkinson's disease: relationship to alphasynuclein inclusions. Neurobio Dis, 35:385-398.

[95] Zhou H, Cao F, Wang Z, Yu ZX, Nguyen HP, Evans J et al (2003). Huntingtin forms toxic NH2-terminal fragment complexes that are promoted by the age- 
dependent decrease in proteasome activity. J Cell Biol, 163:109-118.

[96] Yang DS, Stavrides P, Mohan PS, Kaushik S, Kumar A, Ohno M et al (2011). Reversal of autophagy dysfunction in the TgCRND8 mouse model of Alzheimer's disease ameliorates amyloid pathologies and memory deficits. Brain, 134:258-277.

[97] Tizon B, Sahoo S, Yu H, Gauthier S, Kumar AR, Mohan $P$ et al (2010). Induction of autophagy by cystatin $\mathrm{C}$ : a mechanism that protects murine primary cortical neurons and neuronal cell lines. PLoS ONE, 5:e9819.

[98] Mueller-Steiner S, Zhou Y, Arai H, Roberson ED, Sun B, Chen J et al (2006). Antiamyloidogenic and neuroprotective functions of cathepsin B: implications for Alzheimer's disease. Neuron, 51:703-714.

[99] Dranka BP, Benavides GA, Diers AR, Giordano S, Zelickson BR, Reily C et al (2011). Assessing bioenergetic function in response to oxidative stress by metabolic profiling. Free Radic Biol Med, 51:16211635.

[100] Salabei JK, Gibb AA, Hill BG (2014). Comprehensive measurement of respiratory activity in permeabilized cells using extracellular flux analysis. Nat Protoc, 9:421-438.

[101] Ballinger SW, Patterson C, Yan CN, Doan R, Burow DL, Young CG et al (2000). Hydrogen peroxide- and peroxynitrite-induced mitochondrial DNA damage and dysfunction in vascular endothelial and smooth muscle cells. Circ Res, 86:960-966.

[102] Ballinger SW, Van HB, Jin GF, Conklin CA, Godley BF (1999). Hydrogen peroxide causes significant mitochondrial DNA damage in human RPE cells. Exp Eye Res, 68:765-772.

[103] Ballinger SW, Bouder TG, Davis GS, Judice SA, Nicklas JA, Albertini RJ (1996). Mitochondrial genome damage associated with cigarette smoking. Cancer Res, 56:5692-5697.

[104] Wallace DC, Lott MT, Shoffner JM, Ballinger S (1994). Mitochondrial DNA mutations in epilepsy and neurological disease. Epilepsia, 35 Suppl 1:S43-S50.

[105] Ballinger SW, Shoffner JM, Hedaya EV, Trounce I, Polak MA, Koontz DA et al (1992). Maternally transmitted diabetes and deafness associated with a 10.4 kb mitochondrial DNA deletion. Nat Genet, 1:11-15.

[106] Kalyanaraman B, Darley-Usmar V, Davies KJ, Dennery PA, Forman HJ, Grisham MB et al (2012). Measuring reactive oxygen and nitrogen species with fluorescent probes: challenges and limitations. Free Radic Biol Med, 52:1-6.

[107] Bailey SM, Andringa KK, Landar A, rley-Usmar VM (2008). Proteomic approaches to identify and characterize alterations to the mitochondrial proteome in alcoholic liver disease. Methods Mol Biol, 447:369380 .

[108] Higdon AN, Benavides GA, Chacko BK, Ouyang X, Johnson MS, Landar A et al (2012). Hemin causes mitochondrial dysfunction in endothelial cells through promoting lipid peroxidation: the protective role of autophagy. Am J Physiol Heart Circ Physiol, 302:H1394-H1409.

[109] Mitchell T, Johnson MS, Ouyang X, Chacko BK, Mitra $\mathrm{K}$, Lei X et al (2013). Dysfunctional mitochondrial bioenergetics and oxidative stress in Akita+/Ins2derived beta-cells. Am J Physiol Endocrinol Metab, 305:E585-E599.

[110] Benavides GA, Liang Q, Dodson M, Darley-Usmar V, Zhang J (2013). Inhibition of autophagy and glycolysis by nitric oxide during hypoxia-reoxygenation impairs cellular bioenergetics and promotes cell death in primary neurons. Free Radic Biol Med, 65:1215-1228.

[111] Liang Q, Benavides GA, Vassilopoulos A, Gius D, Darley-Usmar V, Zhang J (2013). Bioenergetic and autophagic control by Sirt3 in response to nutrient deprivation in mouse embryonic fibroblasts. Biochem J, 454:249-257.

[112] Boyer-Guittaut M, Poillet L, Liang Q, Bole-Richard E, Ouyang X, Benavides GA et al (2014). The role of GABARAPL1/GEC1 in autophagic flux and mitochondrial quality control in MDA-MB-436 breast cancer cells. Autophagy, 10:986-1003.

[113] Levonen AL, Hill BG, Kansanen E, Zhang J, DarleyUsmar VM (2014). Redox regulation of antioxidants, autophagy, and the response to stress: Implications for electrophile therapeutics. Free Radic Biol Med, 71C:196-207.

[114] Mitchell T, Chacko B, Ballinger SW, Bailey SM, Zhang J, Darley-Usmar V (2013). Convergent mechanisms for dysregulation of mitochondrial quality control in metabolic disease: implications for mitochondrial therapeutics. Biochem Soc Trans, 41:127-133.

[115] Jegga AG, Schneider L, Ouyang X, Zhang J (2011). Systems biology of the autophagy-lysosomal pathway. Autophagy, 7:477-489.

[116] Jaber N, Dou Z, Chen JS, Catanzaro J, Jiang YP, Ballou LM et al (2012). Class III PI3K Vps34 plays an essential role in autophagy and in heart and liver function. Proc Natl Acad Sci U S A, 109:2003-2008.

[117] Jaber N, Dou Z, Lin RZ, Zhang J, Zong WX (2012). Mammalian PIK3C3/VPS34: the key to autophagic processing in liver and heart. Autophagy, 8:707-708.

[118] Wani WY, Boyer-Guittaut M, Dodson M, Chatham J, Darley-Usmar V, Zhang J (2015). Regulation of autophagy by protein post-translational modification. Lab Invest, 95:14-25.

[119] Schneider L, Giordano S, Zelickson BR, Johnson S, Benavides A, Ouyang X et al (2011). Differentiation of SH-SY5Y cells to a neuronal phenotype changes cellular bioenergetics and the response to oxidative stress. Free Radic Biol Med, 51:2007-2017.

[120] Giordano S, Lee J, Darley-Usmar VM, Zhang J (2012). Distinct Effects of Rotenone, 1-methyl-4phenylpyridinium and 6-hydroxydopamine on Cellular Bioenergetics and Cell Death. PLoS ONE, 7:e44610.

[121] Dodson M, Liang Q, Johnson MS, Redmann M, Fineberg N, Darley-Usmar VM et al (2013). Inhibition of glycolysis attenuates 4-hydroxynonenal-dependent autophagy and exacerbates apoptosis in differentiated 
SH-SY5Y neuroblastoma cells. Autophagy, 9:19962008.

[122] Priyadarshi A, Khuder SA, Schaub EA, Priyadarshi SS (2001). Environmental risk factors and Parkinson's disease: a metaanalysis. Environ Res, 86:122-127.

[123] Priyadarshi A, Khuder SA, Schaub EA, Shrivastava S (2000). A meta-analysis of Parkinson's disease and exposure to pesticides. Neurotoxicology, 21:435-440.

[124] van der MM, Brouwer M, Kromhout H, Nijssen P, Huss A, Vermeulen R (2012). Is pesticide use related to Parkinson disease? Some clues to heterogeneity in study results. Environ Health Perspect, 120:340-347.

[125] Pezzoli G, and Cereda E (2013). Exposure to pesticides or solvents and risk of Parkinson disease. Neurology, 80:2035-2041.

[126] Betarbet R, Sherer TB, MacKenzie G, Garcia-Osuna M, Panov AV, Greenamyre JT (2000). Chronic systemic pesticide exposure reproduces features of Parkinson's disease. Nat Neurosci, 3:1301-1306.

[127] Inden M, Kitamura Y, Abe M, Tamaki A, Takata K, Taniguchi $\mathrm{T}$ (2011). Parkinsonian rotenone mouse model: reevaluation of long-term administration of rotenone in C57BL/6 mice. Biol Pharm Bull, 34:92-96.

[128] Giordano S, Dodson M, Ravi S, Redmann M, Ouyang X, Darley Usmar VM et al (2014). Bioenergetic adaptation in response to autophagy regulators during rotenone exposure. J Neurochem, 131:625-633.

[129] Lee HJ, Cho ED, Lee KW, Kim JH, Cho SG, Lee SJ (2013). Autophagic failure promotes the exocytosis and intercellular transfer of alpha-synuclein. Exp Mol Med, 45:e22.

[130] Liang Q, Ouyang X, Schneider L, Zhang J (2011). Reduction of mutant huntingtin accumulation and toxicity by lysosomal cathepsins D and B in neurons. Mol Neurodegener, 6:37.

[131] Tanik SA, Schultheiss CE, Volpicelli-Daley LA, Brunden KR, Lee VM (2013). Lewy body-like alphasynuclein aggregates resist degradation and impair macroautophagy. J Biol Chem, 288:15194-15210.

[132] Decressac M, Mattsson B, Weikop P, Lundblad M, Jakobsson J, Bjorklund A (2013). TFEB-mediated autophagy rescues midbrain dopamine neurons from alpha-synuclein toxicity. Proc Natl Acad Sci U S A, 110:E1817-E1826.

[133] Kilpatrick K, Zeng Y, Hancock T, Segatori L (2015). Genetic and Chemical Activation of TFEB Mediates Clearance of Aggregated alpha-Synuclein. PLoS ONE, 10:e0120819.

[134] Tsujimura A, Taguchi K, Watanabe Y, Tatebe H, Tokuda T, Mizuno T et al (2014). Lysosomal enzyme cathepsin B enhances the aggregate forming activity of exogenous alpha-synuclein fibrils. Neurobiol Dis, 73C:244-253.

[135] Schapira AH, and Gegg M (2011). Mitochondrial contribution to Parkinson's disease pathogenesis. Parkinsons Dis, 2011:159160.

[136] Murphy MP (2009). How mitochondria produce reactive oxygen species. Biochem J, 417:1-13.

[137] Keeney PM, Xie J, Capaldi RA, Bennett JP, Jr. (2006). Parkinson's disease brain mitochondrial complex I has oxidatively damaged subunits and is functionally impaired and misassembled. J Neurosci, 26:5256-5264.

[138] Devi L, Raghavendran V, Prabhu BM, Avadhani NG, Anandatheerthavarada HK (2008). Mitochondrial import and accumulation of alpha-synuclein impair complex I in human dopaminergic neuronal cultures and Parkinson disease brain. J Biol Chem, 283:90899100.

[139] Hsu LJ, Sagara Y, Arroyo A, Rockenstein E, Sisk A, Mallory M et al (2000). alpha-synuclein promotes mitochondrial deficit and oxidative stress. Am J Pathol, 157:401-410.

[140] Martin LJ, Pan Y, Price AC, Sterling W, Copeland NG, Jenkins NA et al (2006). Parkinson's disease alphasynuclein transgenic mice develop neuronal mitochondrial degeneration and cell death. J Neurosci, 26:41-50.

[141] Lin X, Parisiadou L, Gu XL, Wang L, Shim H, Sun L et al (2009). Leucine-rich repeat kinase 2 regulates the progression of neuropathology induced by Parkinson'sdisease-related mutant alpha-synuclein. Neuron, 64:807-827.

[142] Liu G, Zhang C, Yin J, Li X, Cheng F, Li Y et al (2009). alpha-Synuclein is differentially expressed in mitochondria from different rat brain regions and dosedependently down-regulates complex I activity. Neurosci Lett, 454:187-192.

[143] Chinta SJ, Mallajosyula JK, Rane A, Andersen JK (2010). Mitochondrial alpha-synuclein accumulation impairs complex I function in dopaminergic neurons and results in increased mitophagy in vivo. Neurosci Lett, 486:235-239.

[144] Zhu Y, Duan C, Lu L, Gao H, Zhao C, Yu S et al (2011). alpha-Synuclein overexpression impairs mitochondrial function by associating with adenylate translocator. Int J Biochem Cell Biol, 43:732-741.

[145] Nakamura K, Nemani VM, Azarbal F, Skibinski G, Levy JM, Egami K et al (2011). Direct membrane association drives mitochondrial fission by the Parkinson disease-associated protein alpha-synuclein. J Biol Chem, 286:20710-20726.

[146] Sarafian TA, Ryan CM, Souda P, Masliah E, Kar UK, Vinters HV et al (2013). Impairment of mitochondria in adult mouse brain overexpressing predominantly fulllength, N-terminally acetylated human alpha-synuclein. PLoS ONE, 8:e63557.

[147] Mejias R, Villadiego J, Pintado CO, Vime PJ, Gao L, Toledo-Aral JJ et al (2006). Neuroprotection by transgenic expression of glucose-6-phosphate dehydrogenase in dopaminergic nigrostriatal neurons of mice. J Neurosci, 26:4500-4508.

[148] Ebadi M, Brown-Borg H, El RH, Singh BB, Garrett S, Shavali $S$ et al (2005). Metallothionein-mediated neuroprotection in genetically engineered mouse models of Parkinson's disease. Brain Res Mol Brain Res, 134:67-75.

[149] Yacoubian TA, and Standaert DG (2009). Targets for neuroprotection in Parkinson's disease. Biochim Biophys Acta, 1792:676-687. 
[150] Giordano S, Darley-Usmar V, Zhang J (2014). Autophagy as an essential cellular antioxidant pathway in neurodegenerative disease. Redox Biol, 2:82-90. 